\title{
Antagonistic and Antioxidant efficiency of bacterial pigment isolated from Chromobacterium violaceum (BRT-GR2)
}

\author{
Ramya Gunasekaran $^{1}$, Hemapriya Janarthanam ${ }^{2}$ and Vijayanand Selvaraj ${ }^{1 *}$ \\ ${ }^{1}$ Bioresource Technology Lab, Department of Biotechnology, Thiruvalluvar University, \\ Vellore, Tamil Nadu- 632 115, India \\ ${ }^{2}$ Department of Microbiology, DKM College for Women, Sainathapuram, Vellore, \\ Tamil Nadu- 632 001, India \\ *Corresponding author
}

\section{A B S T R A C T}

\begin{tabular}{|l|}
\hline Ke y w or d s \\
Antibacterial, \\
Bacterial pigments, \\
$\begin{array}{l}\text { Chromobacterium } \\
\text { violacein, } \\
\text { Optimization }\end{array}$ \\
\hline Article Info \\
\hline $\begin{array}{l}\text { Accepted: } \\
\text { 28 June 2020 } \\
\text { Available Online: } \\
\text { 10 July 2020 }\end{array}$ \\
\hline
\end{tabular}

Bacterial pigments play an essential role in the defense mechanism of bacterial system against environmental stress. Bacterial pigments are unique secondary metabolite which exhibits various applications such as antibacterial activity against multidrug resistant strains, antioxidant efficiency against radical molecules, anti-inflammatory, anticancerous properties. In the present study, we concentrated on isolating blue pigment producing bacteria Chromobacterium violaceum (BRT-GR3). The optimum $\mathrm{pH}$ and temperature required for production of pigment with high intensity was found to be $\mathrm{pH} 8$ at $30^{\circ} \mathrm{C}$. The presence of violacein was confirmed by the sharp peak at $567 \mathrm{~nm}$. The pigment exhibited wide range of antibiotic spectrum against Gram positive and Gram negative bacteria used in the study. DPPH radical scavenging efficiency of the pigment was found to be increased with increasing concentration.

\section{Introduction}

Microbes are considered to be the most acquiescing for the production of numerous secondary metabolites such as enzymes, pigments, biosurfactant, amino acids, organic acids, alcohol, and antibiotics. Over other metabolites, microbial colorants have become most essential in the current era due to its wide application in all the fields of science including medicine, photoelectronic, photosensors and food science (Venil and Lakshmanaperumalsamy 2009). Being colorants, they are widely considered in the manufacture of fabrics and cosmetics with antioxidant and antimicrobial properties. Among the vast group, bacteria play an essential role in the production of pigments by utilizing low cost substrate, shorter incubation time, high yield and feasible extraction procedure (Venil et al., 2014). Bacterial pigments have a become a center of attraction 
due to its biological applications such antimicrobial, antioxidant, larvicidal and anticancerous properties. Bacterial posses many properties which make them much easier for handling at large scale production with no seasonal variations (Malik et al., 2012). These bacterial pigments being extracted from biological resource they are less toxic and environment friendly (Cristea and Vilarem 2006). Bacterial pigments obtained from the wild strains are comparatively very less hence to enhance the yield of the wild strain, optimization procedures are highly recommended for better yield at shorter time(Parekh et al., 2000). Carotenoids, Violacein, Prodigiosin, Pyocyanin, Indigoidine, Melanin are the few classic bacterial pigments that were reported to possess various biotechnological applications. Among these, Violacein the blue pigment was reported to possess various application in therapeutics, food and textile industries. Several bacterial species including Janthinobacterium lividum (Pantanella et al., 2007), Chromobacterium violaceum(Rettori and Duran 1998) and Pseudoalteromonas luteoviolacea (Yada et al., 2007) were reported to produce blue pigment. Chromobacterium violaceum is a gramnegative soil bacterium which produce violet pigment violacein with diverse applications. Since only very few bacteria produce blue pigment the application, properties and optimization of pigments are inadequate.

In the present study, Chromobacterium violaceum is been isolated and identified using microbial and molecular approaches. Optimal conditions required for the growth of bacterial such as temperature, $\mathrm{pH}$ and agitation were studied.

Following incubation, pigment extraction was carried out and antibacterial efficiency of the pigment was studied against bacterial pathogens such as Bacillus subtilis, E.coli,
Klebsiella sp. and Shigella sp. Antioxidant efficiency of the pigment was studied using DPPH as free radical.

\section{Materials and Methods}

\section{Sample collection and isolation of bacteria}

For isolation of chromogenic bacteria, various soil samples were collected from Vellore, district, Tamilnadu, India. The soil samples were collected from the depth of $0.5 \mathrm{~cm}$ in a pre-sterilized polythene bag which bears the designation of the sampling site (S1, S2, S3 and S4). The soil samples were transported to laboratory aseptically and stored in refrigerator at $4^{\circ} \mathrm{C}$ to avoid undesirable microbial contaminations.

\section{Isolation of chromogenic bacteria}

The samples collected from various sites were serially diluted using autoclaved water and two fine dilutions were selected for the isolation of the chromogenic colonies. Serially diluted samples were plated over freshly prepared nutrient agar plates and incubated for $48 \mathrm{~h}$ at $30^{\circ} \mathrm{C}$. Following incubation, plates were observed for the presence of chromogenic colonies and designated as BRT-GR1 to BRT-GR3. The isolates were purified using purification techniques and stored as glycerol stock for further use (Sasidharan et al., 2013).

\section{Identification of chromogenic bacteria BRT-GR3}

Based on the intensity and stability of the pigment, BRT-GR3 strain was selected for further study. Microscopic analysis (Colony morphology, and Grams staining) was done to determine the colony morphology and later the isolate was subjected to molecular sequencing for further identification. 


\section{S rDNA sequencing of BRT-GR3}

Chromogenic bacterial strain BRT-GR3 was subjected to genomic DNA isolation using genomic DNA isolation kit procured from Himedia. To $5 \mu \mathrm{l}$ of isolated genome $25 \mu \mathrm{L}$ of PCR reaction solution $(1.5 \mu \mathrm{L}$ of Forward Primer (8F- AGAGTTTGATCCTGG CTCAG) and Reverse Primer (1541RAAGGAGGTGATCCAGCCGCA)), $5 \mu \mathrm{L}$ of deionized water, and $12 \mu \mathrm{L}$ of Taq Master Mix) were added and PCR were set up with respective conditions. The PCR products were purified and subjected to sequencing. Singlepass sequencing was performed on each template using below 16s rRNA universal primers. The fluorescent-labeled fragments were purified from the unincorporated terminators with an ethanol precipitation protocol. The samples were resuspended in distilled water and subjected to electrophoresis. The sequence was refined manually after crosschecking with the raw data to remove ambiguities and was submitted to the Gene Bank and accession number was obtained.

\section{Optimization for enhancing pigment production}

Optimization of bacterial growth factors such as temperature and $\mathrm{pH}$ were optimized in order to outline the appropriate condition required by the bacterial to produce maximum pigment.

\section{Effect of temperature on pigment yield}

In order to determine the suitable temperature for pigment production, the chromogenic strain BRT-GR3 was subjected to various temperatures such as $20^{\circ} \mathrm{C}, 30^{\circ} \mathrm{C}, 40{ }^{\circ} \mathrm{C}, 50$ ${ }^{\circ} \mathrm{C}$ and $60{ }^{\circ} \mathrm{C}$. $50 \mathrm{ml}$ of freshly prepared nutrient broth culture was inoculated with 24 $h$ active culture of BRT-GR3 and incubated at appropriate temperatures for $48 \mathrm{~h}$ to determine the influence of temperature of the pigment. The intensity of the pigment was determined using UV-Visible spectroscopy between 400 to 700 .

\section{Effect of pH on pigment yield}

Chromogenic bacterial isolate BRT-GR3 was subjected to varying $\mathrm{pH}$ for determining the suitable condition for maximizing the pigment production. Freshly prepared nutrient broth culture was inoculated with $24 \mathrm{~h}$ active culture and the $\mathrm{pH}$ range was altered using $\mathrm{NaOH}$ and $\mathrm{HCl}$ as $\mathrm{pH}$ modifiers. The culture tubes were incubated for $48 \mathrm{~h}$ with various $\mathrm{pH}$ like acidic (1 and 2), neutral (6,7 and 8) and basic $(9,10$ and 11). The intensity of the pigment production was determined using $\mathrm{UV}-\mathrm{V}$ is spectroscopy between 400 to $700 \mathrm{~nm}$.

\section{Extraction and purification of bacterial pigment}

$100 \mathrm{ml}$ of freshly prepared nutrient broth culture was inoculated with loopful culture of BRT-GR3 and incubated at optimized culture condition at $150 \mathrm{rpm}$ for $48 \mathrm{~h}$. Prior incubation, the culture media was collected in a sterile centrifuging tube and centrifuged at $8000 \mathrm{rpm}$ for 15 minutes. The supernatant was discarded and the pellet was washed with distilled water to remove the adhered nutrient broth residues. The pellet was further centrifuged and treated with ethanol and incubated for $3 \mathrm{~h}$. Further incubation, the solvent-pellet mixture was centrifuged where, the colored supernatant was collected in a sterile tube and the decolorized pellet was discarded (Asencio et al., 2014).

\section{UV- Visible spectrophotometric analysis of the pigment}

To confirm the presence of violacein pigment, one $\mathrm{ml}$ of the extracted bacteria pigment was taken and analyzed for the presence of pigment against ethanol as blank. The maximum absorbance range was determined using JASCO V-730 UV-Visible Spectro- 
photometry between the range 450 to $700 \mathrm{~nm}$.

\section{Antagonistic ability of bacterial pigment}

The extracted bacterial pigment was evaluated for its antagonistic ability against bacterial pathogens such as Bacillus sp., E. coli, Klebsiella sp., and Shigella sp. The experiment was carried out on freshly prepared Muller Hinton agar plate using well diffusion method. The wells were made on the agar plate using sterile well cutter. The antagonistic ability of the pigment was demonstrated using varying concentration $(20 \mu \mathrm{g} / \mathrm{ml}$ to $100 \mu \mathrm{g} / \mathrm{ml})$. The plates were incubated at $37^{\circ} \mathrm{C}$ for $24 \mathrm{~h}$. The zone of inhibition around the well was observed and recorded (Kanelli et al., 2018).

Free radical scavenging ability of the pigment

DPPH (2, 2-Diphenyl-1- picrylhydrazyl) free radical scavenging activity of the bio colorant was measured by DPPH method.A solution of DPPH $0.1 \mathrm{mM}$ in ethanol was prepared. $1 \mathrm{ml}$ of the solution was added to $3 \mathrm{ml}$ of the pigment fraction in ethanol at different concentrations $(100 \mu \mathrm{g}$ to $500 \mu \mathrm{g} / \mathrm{ml})$, mixture was shaken and allowed to stand at room temperature for $1 \mathrm{~h}$ (Konzen et al., 2007). The absorbance was taken at $517 \mathrm{~nm}$ by using UV Visible spectrophotometer. The percentage of DPPH scavenging effect was calculated using the following equation.

\section{DPPH scavenging effect $(\%)=A_{0}-A_{1} / A_{0} \times 100$}

Where, $\mathrm{A}_{0}$ is the absorbance of control (Ascorbic acid) and $\mathrm{A}_{1}$ is the absorbance of test sample (pigment).

\section{Results and Discussion}

\section{Isolation of pigment producing bacteria}

Among three chromogenic bacterial colonies isolated from the soil samples,a single bacterial strain was found to produce unique blue color pigment with high intensity. The mixed culture plate has been depicted in Fig 1. The pigment producing strain was designated as BRT- GR3 and preserved as slant at $4^{\circ} \mathrm{C}$ for further uses (Fig 2).Various study reported the isolation of violet/blue pigment producing bacteria from soil sample. According to earlier study, violet pigment producing psychrotrophic bacteria Janthinobacterium lividum XT1 has been isolated from glaciers in China ( $\mathrm{Lu}$ et al., 2009).

Similarly, Chromobacterium violaceum has been isolated from the soils of Kolli hills, Tamil Nadu and studied for its larvicidal efficiency (Baskar and Ignacimuthu 2012).The colony was found to be smooth, shiny, round, convex and pigment producing in nature. The microscopic study shows that the isolate is Gram negative coccobacillus.

\section{S rDNA sequencing of BRT-GR3}

A total of 1432 bases sequence of PCR amplified 16S r DNA gene was determined from the isolate BRT- GR3 (Fig 3) which corresponds to more than $99 \%$ of the gene sequence. In the analysis at NCBI and RDP sites it showed homology to $16 \mathrm{~S} \mathrm{r}$ DNA sequences from Chromobacterium species.

In the phylogenetic analysis, the sequence formed a cluster within Chromobacterium species with $100 \%$ boot strap value, confirming the identity of the isolate as strain of this species. The highest similarity value exists with Chromobacterium sp. with the accession number JF734316.1. The bacterial strain BRT- GR3 was identified as Chromobacterium violaceum with the NCBI accession ID MF144240. The phylogenetic relationship between the strain BRT- GR3 and other related strains were shown in (Fig 4). 


\section{Optimization of culture conditions}

\section{Effect of $\mathrm{pH}$ and temperature on pigment production}

Optimization of culture condition and biomass production was done in order to enhance the production of biomass and secondary metabolite formation. Bacterial strain was subjected to various $\mathrm{pH}$ condition in order to determine the maximum yield and the intensity of the bacterial pigment was found to high at $\mathrm{pH} 8$ (Fig 5). Similarly the production of violacein was found to be maximum between $\mathrm{pH} 7$ and 9 (Palukurty et al., 2016).Maximum yield was observed at the temperature of $30^{\circ} \mathrm{C}$ (Fig 6). According to the earlier study, the optimum temperature required for maximizing the intensity of the pigment was 25 to $30^{\circ} \mathrm{C}$ where, the pigment showed more stability on storage (Venil et al., 2015).

\section{Extraction and characterization of pigment}

The $48 \mathrm{~h}$ old culture broth was centrifuged and the intercellular pigment was extracted using solvent extraction method (Fig. 7). The absorption spectrum for the ethanolic extract was studied using UV-visible spectrophotometry. The absorption maxima for the extracted pigment were observed at $567 \mathrm{~nm}$, which was a typical pattern of absorption spectrum of violacein. The sharp peak at indicated the presence of violacein. The obtained UV-Vis spectrum has been shown in Fig8.

\section{Antagonistic ability of pigment from BRT- GR3}

The extracted bacterial pigment was evaluated for its antibacterial activity against bacterial pathogens such as Bacillus subtilis, E.coli, Klebsiella sp. and Shigella sp.on freshly prepared Muller Hinton agar plate using well diffusion method. The bacterial pigment was tested for its antibacterial activity against bacterial pathogens with varying concentration $(20 \mu \mathrm{g} / \mathrm{ml}$ to $100 \mu \mathrm{g} / \mathrm{ml})$ (Fig 9). Chloramphenicol was used as positive control and ethanol was used as negative control. At maximum concentration $(100 \mu \mathrm{g} / \mathrm{ml})$,Bacillus sp. exhibited maximum zone of inhibition of $14 \mathrm{~mm}$ whereas, E.coli, exhibited minimal zone of inhibition $(5 \mathrm{~mm})$. Similarly, Janthinobacterium sp. SMN, an Antarctica bacterium was reported to produce blue pigment and the antagonist activity of the bacteria was found to be wide against gram negative pathogenic bacteria (Asencio et al., 2014).

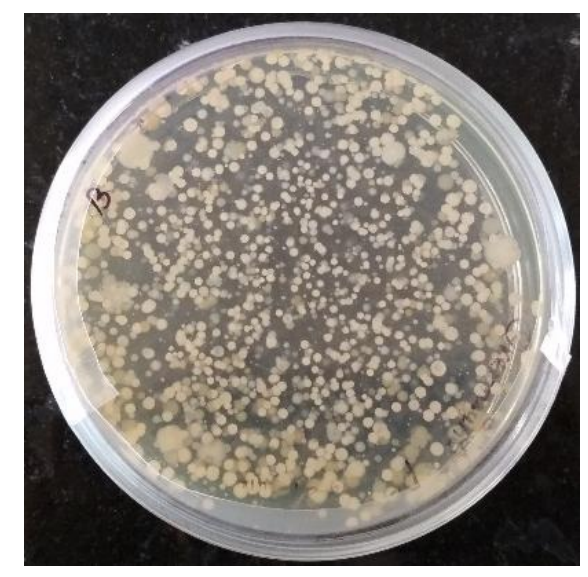

Figure.1 Plate depicting the mixed culture plate of chromogenic bacteria from soil sample 


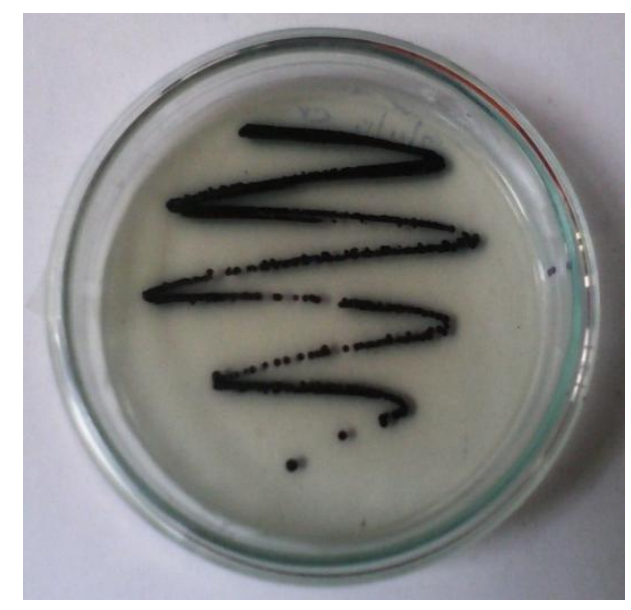

Figure.2 Depicting the pure culture of BRT-GR3

\begin{abstract}
GCAAGTCGAACGGTAACAGGGTGCTTGCACCGCTGACGAGTGGCGAACGGGTGAGTAATGCG TCGGAATGTACCGTGTAATGGGGGATAGCTCGGCGAAAGCCGGATTAATACCGCATACGCCC TGAGGGGGAAAGCGGGGGATCGAAAGACCTCGCGTTATACGAGCAGCCGACGTCTGATTAGC TAGTTGGTGAGGTAAGAGCTCACCAAGGCGACGATCAGTAGCGGGTCTGAGAGGATGATCCG CCACACTGGGACTGAGACACGGCCCAGACTCCTACGGGAGGCAGCAGTGGGGAATTTTGGAC AATGGGGGCAACCCTGATCCAGCCATGCCGCGTGTCTGAAGAAGGCCTTCGGGTTGTAAAGG ACTTTTGTCAGGGAGGAAATCCCGCTGGTTAATACCCGGCGGGGATGACAGTACCTGAAGAA TAAGCACCGGCTAACTACGTGCCAGCAGCCGCGGTAATACGTAGGGTGCGAGCGTTAATCGG AATTACTGGGCGTAAAGCGTGCGCAGGCGGTTGTGCAAGTCTGATGTGAAAGCCCCGGGCTT AACCTTGGGAACGGCATTGGAGACTGCACAGCTAGAGTGCGTCAGAGGGGGGTAGAATTTCC ACGTGTAGCAGTGAAATGCGTAGAGATGTGGAGGAATACCGATGGCGAAGGCAGCCCCCTGG GATGACACTGACGCTCATGCACGAAAGCGTGGGGAGCAAACAGGATTAGATACCCTGGTAGT CCACGCCCTAAACGATGTCAACTAGCTGTTGGGGGTTTGAATCCTTGGTAGCGTAGCTAACGC GTGAAGTTGACCGCCTGGGGAGTACGGCCGCAAGGTTAAAACTCAAAGGAATTGACGGGGAC CCGCACAAGCGGTGGATGATGTGGATTAATTCGATGCAACGCGAAAAACCTTACCTGCTCTT GACATGTACGGAACTTGCCAGAGATGGCTTGGTGCCCGAAAGGGAGCCGTAACACAGGTGCT GCATGGCTGTCGTCAGCTCGTGTCGTGAGATGTTGGGTTAAGTCCCGCAACGAGCGCAACCC TTGTCATTAGTTGCCATCATTAAGTTGGGCACTCTAATGAGACTGCCGGTGACAAACCGGAGG AAGGTGGGGATGACGTCAAGTCCTCATGGCCCTTATGAGCAGGGCTTCACACGTCATACAAT GGTCGGTACAGAGGGTTGCCAAGCCGCGAGGTGGAGCTAATCTCAGAAAACCGATCGTAGTC CGGATCGCACTCTGCAACTCGAGTGCGTGAAGTCGGAATCGCTAGTAATCGCAGATCAGCAT GCTGCGGTGAATACGTTCCCGGGTCTTGTACACACCGCCCGTCACACCATGGGAGTGAGTTTC ACCAGAAGTGGGTAGGCTAACCGTAAGGAGGCCGCTTACCACGGTGGGATTCATGACTGGGG TGA
\end{abstract}

Figure.3 16S rDNA Sequence data of the isolated strain BRT-GR3

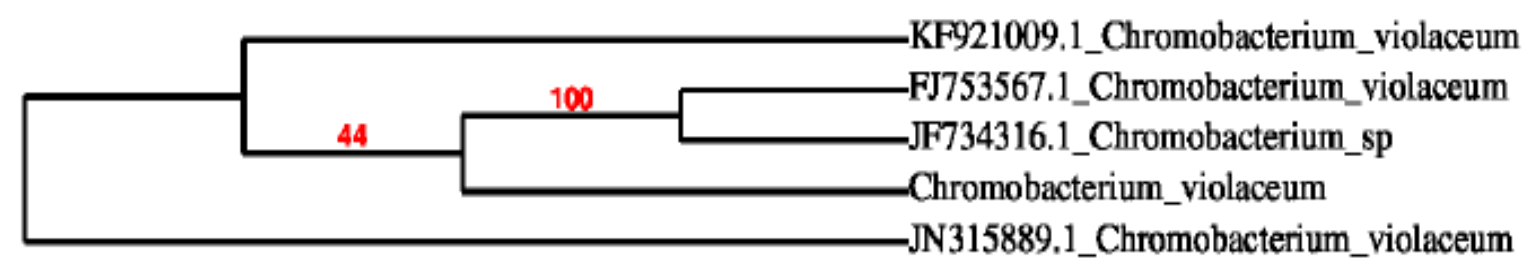

Figure.4 Phylogenetic relationship of the isolate BRT-GR3 


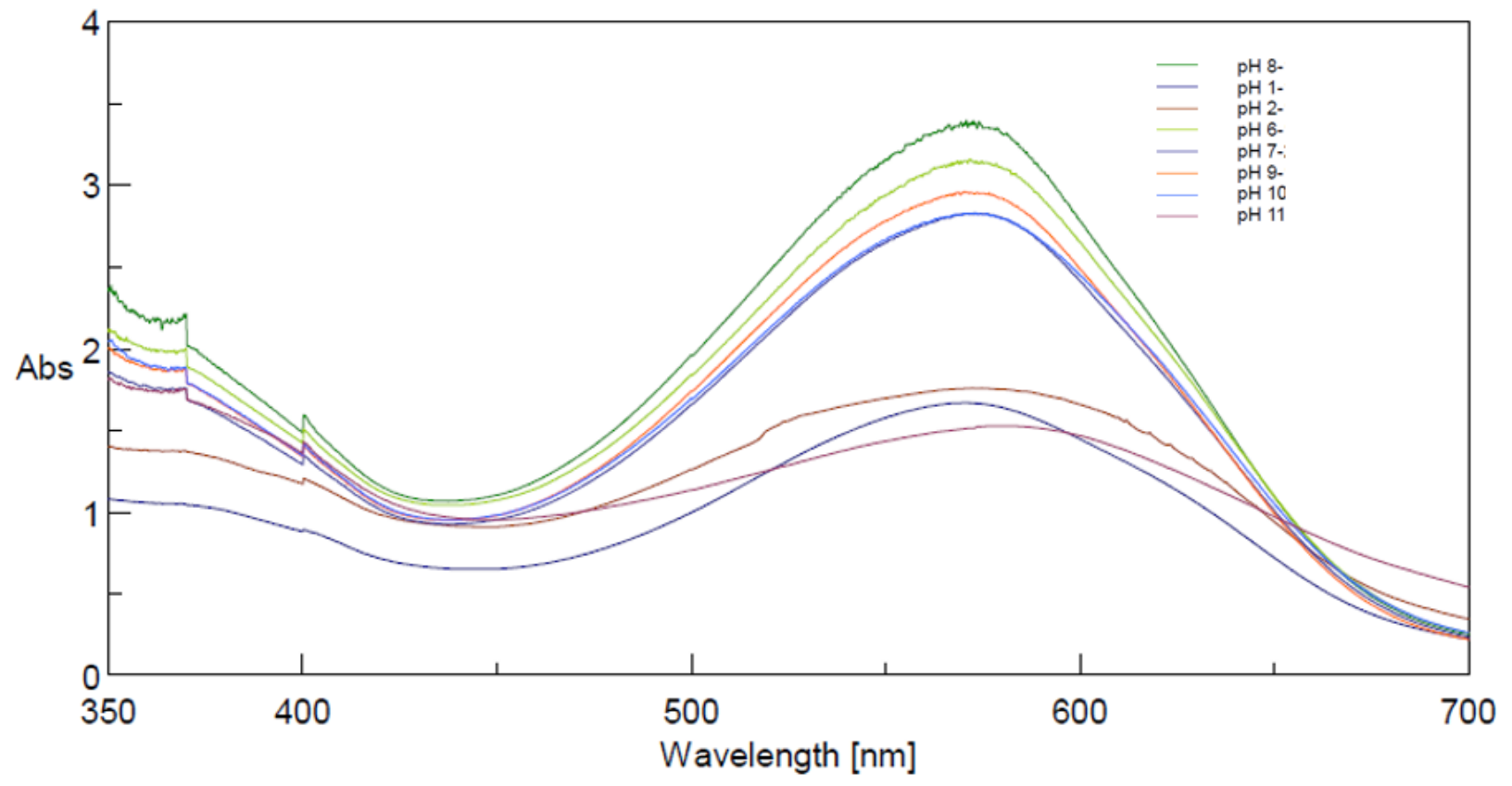

Figure.5 Effect of $\mathrm{pH}$ on the intensity of the pigment from BRT-GR2

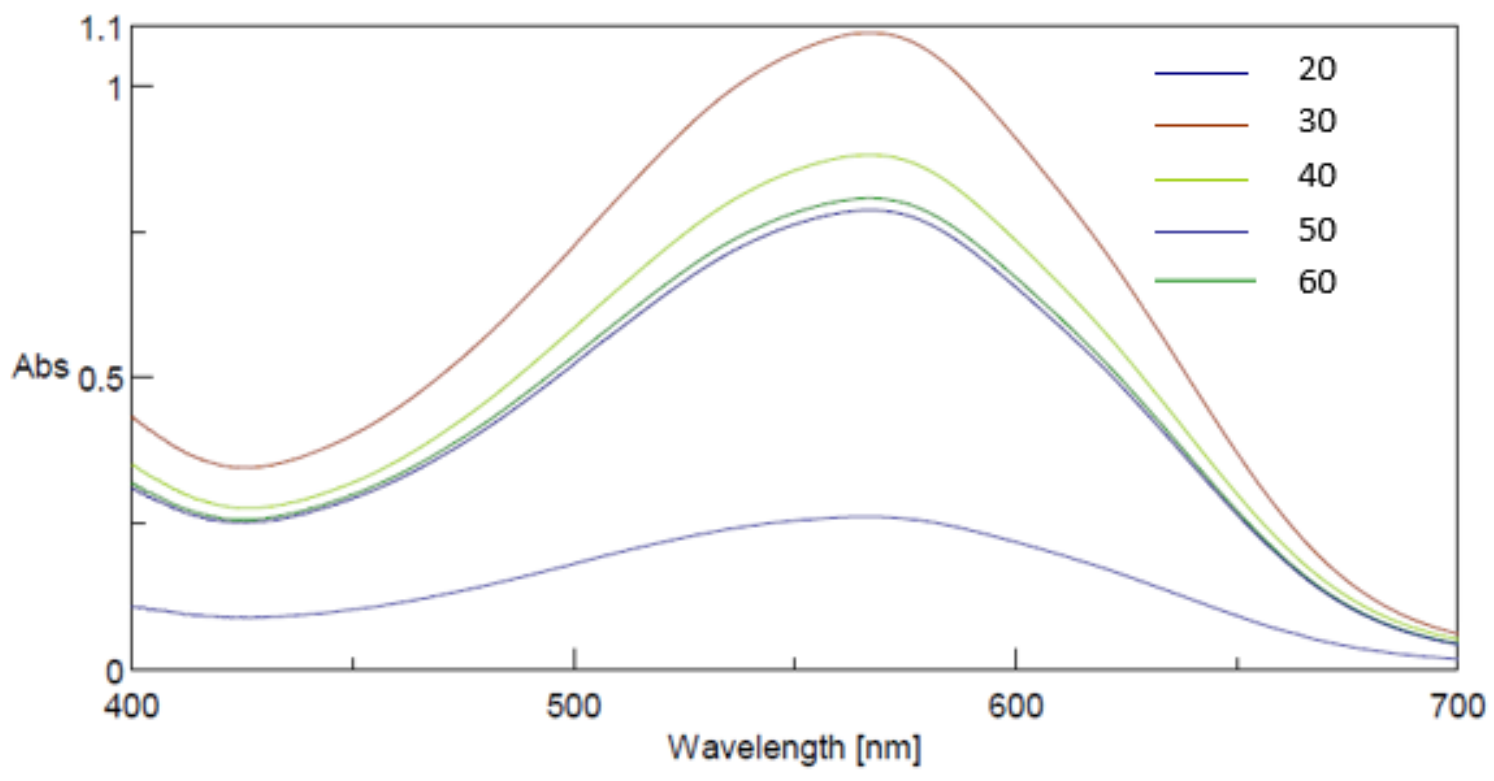

Figure.6 Effect of temperature on the intensity of the pigment from BRT-GR2 


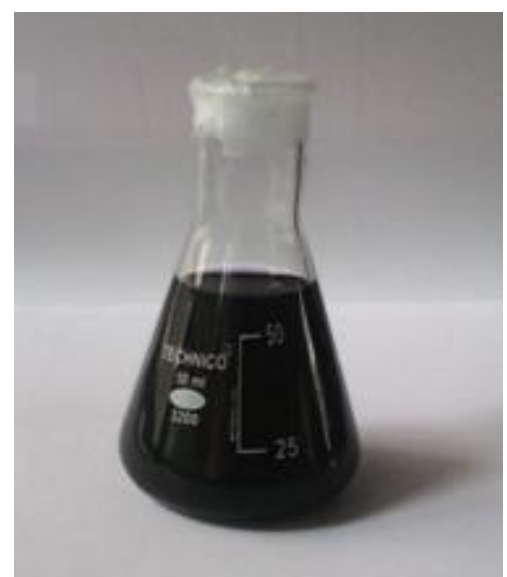

Figure.7 Blue pigment extracted from the isolate BRT-GR3

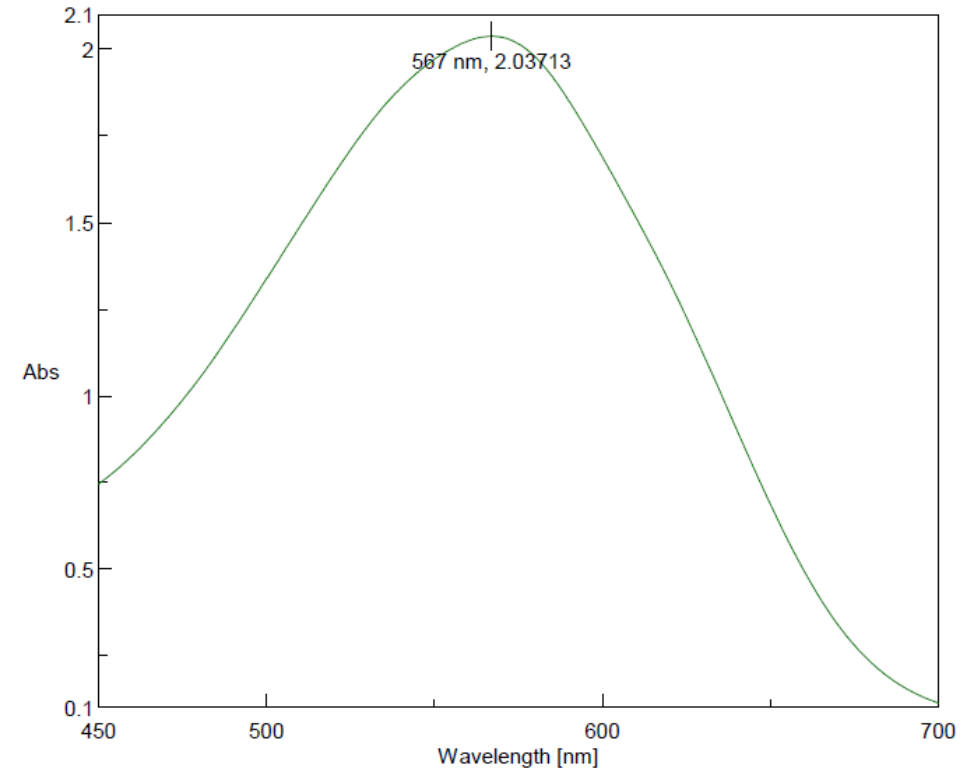

Figure.8 UV-Visible spectra of blue pigment extracted from BRT-GR3

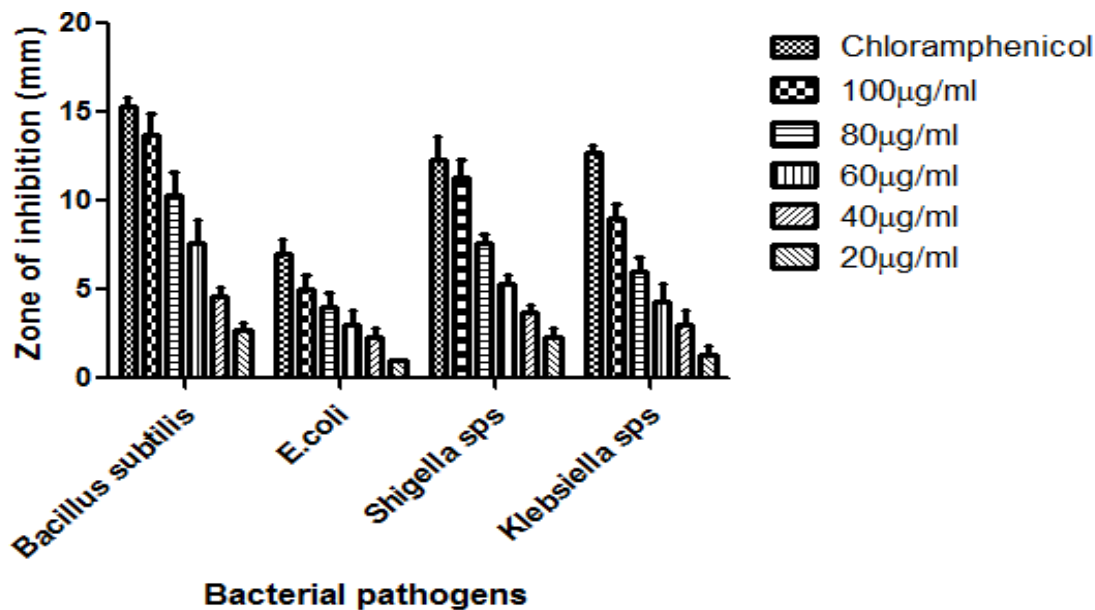

Figure.9 Antagonist activity of bacterial pigment (BRT-GR3) on bacterial pathogens 


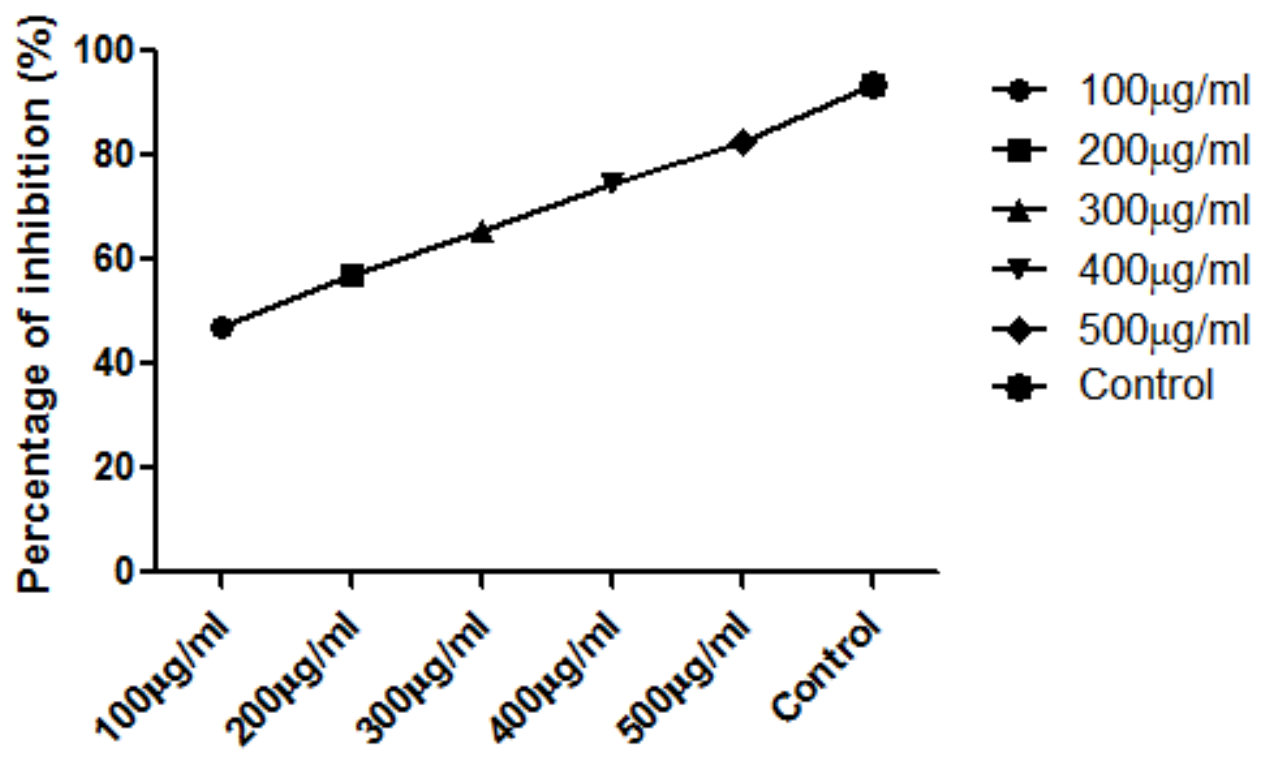

\section{Concentration $(\mu \mathrm{g} / \mathrm{ml})$}

Figure.10 Antioxidant efficiency of pigment extracted from BRT-GR2

\section{Radical scavenging ability of the bacterial pigment}

Bacterial pigment was evaluated for its ability to scavenge the free radical scavenging ability. The DPPH radical scavenging activity has been widely used as a model system to investigate the scavenging activity of natural compounds. In the present study, the bacterial pigment showed scavenging activity in a concentration-dependent manner (Fig 10). In $\mathrm{DPPH}$ free radical scavenging assay, as the concentration of the pigment increased the percentage of inhibition also increased. According to the previous study, it has been reported that violacein exhibited efficient antioxidant activity (Konzen et al., 2007).

In the present study the chromogenic bacteria isolated from the soil sample was identified as Chromobacterium violaceum (BRT-GR3). The optimum $\mathrm{pH}$ and temperature required for the production of pigment with high intensity was determined. The UV-Visible spectroscopic data reveals the presence of
Violacein pigment at $567 \mathrm{~nm}$. Antagonistic activity of the pigment was observed to be higher with increasing concentration. Free radical scavenging ability of the pigment was demonstrated against ascorbic acid as positive control where the percentage of inhibition was found to be higher with increasing concentration. Hence, the study concluded that the versatile blue pigment can act as antibacterial agent against multidrug resistant bacteria and scavenge reactive oxygen species even at lower concentration.

\section{References}

Asencio G, Lavin P, Alegría K, Domínguez M, Bello H, González-rocha G, Gonzálezaravena M (2014) Electronic Journal of Biotechnology Antibacterial activity of the Antarctic bacterium Janthinobacterium sp . SMN 33.6 against multi-resistant Gramnegative bacteria. EJBT 17:1-5 . https://doi.org/10.1016/j.ejbt.2013.12.001

Baskar K, Ignacimuthu S (2012) Bioefficacy of violacein against Asian armyworm Spodoptera litura Fab. (Lepidoptera: 
Noctuidae). J Saudi Soc Agric Sci 11:7377

https://doi.org/10.1016/j.jssas.2011.10.002

Cristea D, Vilarem G (2006) Improving light fastness of natural dyes on cotton yarn. Dye Pigment 70:238-45

Kanelli M, Mandic M, Kalakona M, Vasilakos S, Kekos D, Nikodinovic-runic J, Topakas E (2018) Microbial Production of Violacein and Process Optimization for Dyeing Polyamide Fabrics With Acquired Antimicrobial Properties. Front Microbiol $9: 1-13$ https://doi.org/10.3389/fmicb.2018.01495

Konzen M, Marco D De, Cordova CAS, Vieira TO, Anto R V (2007) Antioxidant properties of violacein: Possible relation on its biological function Antioxidant properties of violacein: Possible relation on its biological function. Bioorg Med Chem 14:8307-8313 https://doi.org/10.1016/j.bmc.2006.09.013

Lu Y, Wang L, Xue Y, Zhang C, Xing XH, Lou K, Zhang Z, Li Y, Zhang G, Bi J, Su Z (2009) Production of violet pigment by a newly isolated psychrotrophic bacterium from a glacier in Xinjiang, China. Biochem Eng J 43:135-141 https://doi.org/10.1016/j.bej.2008.09.009

Malik K, Tokkas J, Goyal S (2012) Microbial pigments: a review. Int $\mathrm{J}$ Microb ResTechnol 1:361-5.

Palukurty A, Pyla S, Silarapu S, Somalanka S (2016) Analyzing Alternative Nutrient Supplements and Optimization of Production Parameters for Violacein using Central Composite... Int J Sci Eng Res 7:294-300

Pantanella F, Berlutti F, Passariello C, Sarli S, Morea C, Schippa S (2007) Viola-cein and biofilm production in Janthinobacterium lividum. J Appl Microbiol 102:992-9.

Parekh S, Vinci V, Strobel R (2000) Improvement of microbial strains and fermen-tation processes. Appl Microbiol Biotechnol 54:287-301.

Rettori D, Duran N (1998) Production, extraction and purification of violacein: an antibiotic pigment produced with Chromobacteria violaceum. World $\mathrm{J}$ Micro-bial Biotechnol 14:685-8

Sasidharan P, Raja R, Karthik C, Sharma R, Arulselvi, Indra P (2013) Isolation and characterization of yellow pigment producing Exiguobacterium sps. 4: J Biochem Tech 4:632-635

Venil C, Lakshmanaperumalsamy P (2009) An insightful overview on microbialpigment: prodigiosin. Ele J Biol 5:49-61

Venil CK, Aruldass CA, Abd Halim MH, Khasim AR, Zakaria ZA, Ahmad WA (2015) Spray drying of violet pigment from Chromobacterium violaceum UTM 5 and its application in food model systems. Int Biodeterior Biodegrad 102:324-329 . https://doi.org/10.1016/j.ibiod.2015.02.006

Venil CK, Aruldass CA, Dufossé L, Zakaria ZA, Ahmad WA (2014) Current perspective on bacterial pigments: emerging sustainable compounds with coloring and biological properties for the industry - an incisive evaluation. RSC Adv 4:39523 https://doi.org/10.1039/C4RA06162D

Yada S, Wang Y, Zou Y, Nagasaki K, Hosokawa K, Osaka I (2007) Isolation andcharacterization of two groups of novel marine bacteria producing violacein. Mar Biotechnol 10:128-32.

\section{How to cite this article:}

Ramya Gunasekaran, Hemapriya Janarthanam and Vijayanand Selvaraj. 2020. Antagonistic and Antioxidant efficiency of bacterial pigment isolated from Chromobacterium violaceum (BRT-GR2). Int.J.Curr.Microbiol.App.Sci. 9(07): 4050-4059.

doi: https://doi.org/10.20546/ijcmas.2020.907.475 